\title{
Characteristics of low-rank coal reservoir and exploration potential in Junggar Basin: new frontier of low-rank CBM exploration in China
}

\author{
Yuanjiang $\mathrm{Yu}^{1} \mathbb{1} \cdot$ Yonghua Wang $^{1}$
}

Received: 17 November 2019 / Accepted: 3 June 2020 / Published online: 15 June 2020

(c) The Author(s) 2020

\begin{abstract}
Low-rank coal reservoirs of Badaowan Formation and Xishanyao Formation are mainly developed in Junggar Basin. This paper discussed their features and coalbed methane (CBM) exploration potential based on geological survey, coal samples testing and mathematical fitting analysis. The pores are mainly small-micro- and large pores, and the porosity is 3.25-27.4\% with an average of 9-10.51\%; and macro-cracks and micro-fissures are well developed leading to a great variation of the permeability. The shallow coal reservoirs are mostly undersaturated, and the gas saturation tends to increase toward the deep coalbed. The $\mathrm{J}_{2} \mathrm{x}$ has a stronger methane adsorption and storage capacity than that of $\mathrm{J}_{1} \mathrm{~b}$ and better physical properties, making CMB recovery easier. The coalbed reservoirs in middle-east of southern margin, eastern part and hinterland of Junggar Basin reach methane-rich to extremely methane-rich coalbeds and have strong ability to adsorb and store CBM. Coal seam gas shows generally, and the measured gas-bearing property is good. Low-rank CBM accounts for the majority of CBM resources in the basin. According to Langmuir volume, the gas provinces are classified into four types of blocks, i.e., CBM-poor $\left(<8 \mathrm{~m}^{3} / \mathrm{t}\right), \mathrm{CBM}$-bearing $\left(8-15 \mathrm{~m}^{3} / \mathrm{t}\right)$, relatively CBM-rich $\left(15-20 \mathrm{~m}^{3} / \mathrm{t}\right)$ and CBM-rich $\left(>20 \mathrm{~m}^{3} / \mathrm{t}\right)$. The relatively CBM-rich blocks cover block of well Qing 1 to Qi 8, Changji-Urumqi-Fukang area and slope belt of northwest margin to basin hinterland; while the CBM-rich blocks include most of eastern Junggar Basin. Since 2005, a series of special exploration and research of CBM have been carried out successively, and significant progress has been made in exploration of deep and shallow combination, conventional (gas) and unconventional (gas) combination. Recently shallow CBM exploration has achieved gas extraction at Dahuangshan coal mine, industrial gas flow wells in western Baiyanghe, and breakthrough of deep CBM exploration in Baijiahai area has been made, which confirmed the great development potential of low-rank CBM. The southern margin and the east of Junggar Basin have become the new frontier of low-rank CBM exploration in China.
\end{abstract}

Keywords Low-rank coal $\cdot$ Reservoir features $\cdot$ Langmuir volume $\cdot$ Langmuir pressure $\cdot$ CBM potential $\cdot$ Junggar Basin

\section{Introduction}

The low-rank coalbed methane (CBM) is a kind of unconventional natural gas existing in the low-rank coal $\left(R_{\mathrm{o}}<0.8 \%\right)$, such as lignite, long flame and gas coals (Yu et al. 2001; Wang et al. 2003). In the past, it was generally considered that the gas content of low-rank coal was small and not suitable for commercial development. In recent years, the USA has taken the lead in obtaining low-rank CBM industrial gas

Yuanjiang Yu

724631322@qq.com

1 Research Institute of Petroleum Exploration and Development (RIPED), PetroChina, No. 20

Xueyuan Road, Haidian District, Beijing 100083, People's Republic of China flows in Powder River, Uinta and Great Green River Basins (Montgomery 1999; Feng et al. 2003; Chen et al. 2007) and has constructed several commercial development zones. China's low-rank CBM resources account for more than $40 \%$ of the total CBM geological resources above $2000 \mathrm{~m}$ depth (Liu et al. 2010; Zhang et al. 2013). Successful development of low-rank CBM in America has brought breakthroughs in theoretical understanding and has also triggered high interests on the low-rank CBM accumulation in China (Sang et al. 2001; Yao 2007; Jia et al. 2015).

Up to now, the exploration and development of low-rank CBM in China is still in the stage of test and small-scale commercialization (Zhang 2016; Li et al. 2016; Chen et al. 2017; Shan et al. 2018), and large-scale commercial exploitation has not yet been realized. In recent years, the study of low-rank CBM mainly focuses on coal geology, hydrocarbon generation 
and accumulation as well as resource evaluation (Yu et al. 2001, 2008; Zhang et al. 2013; Jia et al. 2015) summarizes the theoretical and technical progress of low-rank CBM in America and preliminarily evaluates the geological conditions, resources, characteristics and development prospects of lowrank CBM in China. It is inclined to simply follow the research ideas and traditional methods used in high-rank CBM exploration (Yuan et al. 2018), low understanding of basic geology such as gas generation and storage mechanism, change law of gas content, lack of the gas content test and applicable exploration technology. These result in the overall slow progress of exploration and development of low-rank CBM.

There are abundant coal and CBM resources in the Junggar Basin located in the north of Xinjiang, China. Typical lowrank coal reservoirs are mainly developed, forming the coexistence of CBM and conventional oil and gas in the same basin. However, the coal (rock) has been always considered as source rock in the past (Qin et al. 2005; Liu et al. 2005; Zhao et al. 2005), while the coal reservoir and CBM potential have not been paid attention. In the early 2000s, the CBM resource was roughly evaluated (Chen and Zhang 2003; Wang et al. 2002; Zhang et al. 2002; Wang and Zhang 2002; Chen et al. 2003). Since 2005, the low-rank CBM has been specially researched and explored (Yu et al. 2006; Yang et al. 2005). Great progress has been made in the past 5 years, thus becoming a new frontier of low-rank CBM exploration in China.

On the whole, the exploration and development of CBM in Junggar Basin started late, and the evaluation of characteristic parameters and potential of low-rank coal reservoir is few, the gas content measurement data are few, and the comprehensive research level is low. In view of this, based on the traditional geological survey and coal mine profile observation and sampling, advanced coal reservoir parameter test and isothermal adsorption test analysis, this paper carries out the resource potential and selection evaluation of low-rank CBM and puts forward the new understanding of low-rank coal reservoir characteristics, adsorption and productivity, exploration potential and gas-bearing favorable area. This is beneficial to Junggar Basin, and even the similar low-rank CBM exploration at home and abroad has important theoretical and practical significance, which will provide theoretical basis and decision-making reference for the exploration direction of low-rank CBM and the optimization of natural gas reserves replacement field.

\section{Geological conditions of CBM}

\section{Tectonic settings and coal-bearing strata system}

Junggar Basin is located in the north of Xinjiang, northwestern China. It is surrounded by fold mountain system, West Junggar mountain system (Zayier Mountain to Hala'alat
Mountain to Delun Mountain) in the northwest, Altai mountain system (Qinggelidi Mountain to Kerameili Mountain) in the northeast and Tianshan mountain range (Yilinheibiergen Mountain to Bogda Mountain) in the south. It is a large coal-bearing basin with roughly irregular triangle (Fig. 1), covering an area of $13.4 \times 10^{4} \mathrm{~km}^{2}$.

The Junggar Basin can be divided into six class-I tectonic units (Fig. 1), which are "three uplifts (Western uplift, Luliang uplift, Eastern uplift), two depressions (Central depression, Wulungu depression), one thrust belt (North Tianshan piedmont thrust belt)," and 44 class-II tectonic units. The hinterland of the basin is characterized by inherited wide and gentle depression and uplift deformation, with relatively undeveloped faults and fold structures; the marginal area is dominated by thrust napped deformation formed by lateral compression, with a series of compressional and torsional faults, folds and nappes parallel to the mountain system developed, which has an important impact on CBM accumulation.

The coal-bearing strata in Junggar Basin are Jurassic system, which are successively developed the lower Jurassic Badaowan Fm. $\left(J_{1} b\right)$, Sangonghe Fm. $\left(J_{1} s\right)$, Middle Jurassic Xishanyao Fm. $\left(\mathrm{J}_{2} \mathrm{x}\right)$, Toutunhe Fm. $\left(\mathrm{J}_{2} \mathrm{t}\right)$, Upper Jurassic Qigu Fm. $\left(J_{3} q\right)$ and Kalazar Fm. $\left(J_{3} k\right)$ from the bottom to the top. See Fig. 2 for the lithology characteristics. Among them, the middle to lower Jurassic is the development period of continental coal-bearing formation, and two sets of coal measures strata (Fig. 2) of Badaowan Fm. ( $\left.\mathrm{J}_{1} \mathrm{~b}\right)$ and Xishanyao Fm. $\left(\mathrm{J}_{2} \mathrm{x}\right)$ are widely deposited, which are the most important two industrial coal production horizons and the main source layers of CBM.

The coal measure strata of middle to lower Jurassic are widely distributed in the whole basin and are deeply buried in the abdomen and the southern margin of the basin. Badaowan Fm. $\left(J_{1} b\right)$ is mainly composed of alluvial fan, fan delta to river and swamp facies coal-bearing deposits, which are $200-700 \mathrm{~m}$ thick. The Xishanyao Fm. $\left(\mathrm{J}_{2} \mathrm{x}\right)$ is deposited continuously on the Sangonghe Fm., which is a set of delta, lake to river swamp facies deposit with a thickness of 50-1000 m. They are rich in coal and CMB, coexisting with the conventional oil and gas.

\section{Coal type and coal rank distribution}

The coalbed of Badaowan Fm. is mainly long flame coal and non-caking coal in the northwest and east of the basin; mainly long flame coal and gas coal in the western Urumqi River, followed by weakly caking coal and non-caking coal; fat coal and gas coal in the eastern Urumqi River of southern margin in Junggar Basin.

The coalbed of Xishanyao Fm. is mainly lignite, long flame coal and non-caking coal in the northwest margin of Junggar Basin; non-caking coal is mainly developed 


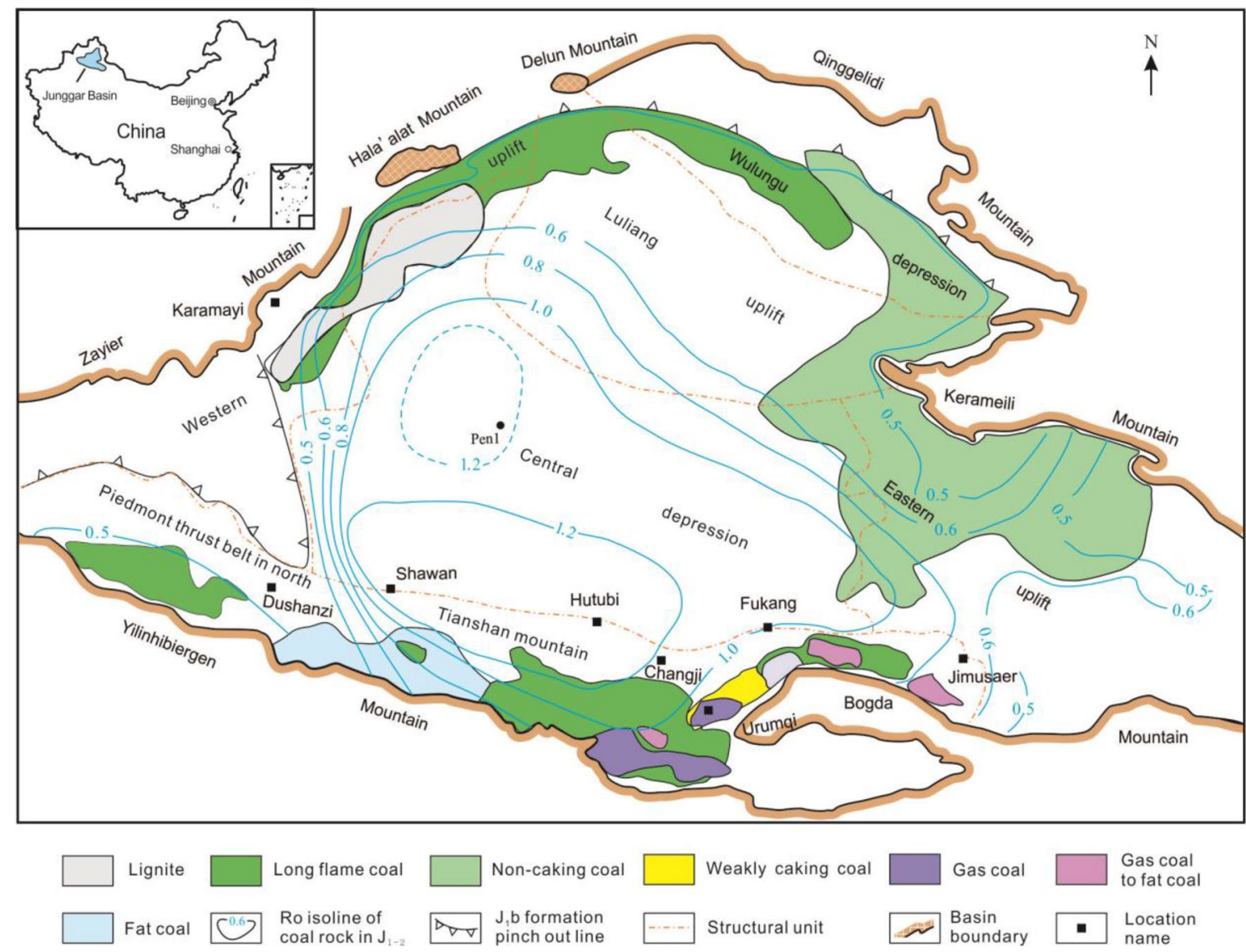

Fig. 1 Structural unit, Ro isolines of middle-lower Jurassic and margin distribution of coal types in Junggar Basin

in the east of Junggar Basin, with a small amount of gas coal, weakly caking coal and long flame coal; gas coal and weakly caking coal are mainly developed in southern margin of Junggar Basin, followed by long flame coal, with a small amount of fat coal, fat to gas coal and non-caking coal. Generally speaking, the coal seams are mainly long flame coal and non-caking coal in the north of the basin, weakly caking coal and gas coal in the south of the basin (Fig. 1). The coal type's distribution and coal metamorphism are low in the north and high in the south, low in the West and high in the East.

It can be seen from Fig. 1, coal mine and profile data that Ro distribution of coal rock in Junggar Basin are from 0.40 to $1.01 \%$, mostly $0.45-0.8 \%$, coal grade distribution is low in the north and high in the south, low in coal mine and surface profile, high in underground drilling, high value area with more than $1.0 \%$ of Ro is confined to Shawan to Hutubi areas in the southern margin and Peng1 well area in abdomen of the basin. The coal rank is generally low, mainly low-rank long flame coal, so the main part belongs to typical low-rank coal reservoir.

\section{Sample collection and research methods}

\section{Sample collection}

The authors have carried out field investigation of coalbed methane in Junggar Basin. During the geological investigation, 6 coal mining areas (Urumqi, Fukang and Changji Liuhuanggou in the southern margin; Mulei, Balikun and Santanghu mining areas in the east of the basin) were surveyed. The underground coal lane was observed for $500 \mathrm{~m}$, and a total of 217 samples of 8 types were collected and analyzed (Table 1).

To make the study more comprehensive and objectively reflect the geological characteristics as much as possible, some of the previous sample data were collected. In addition to one sample collected from a borehole, the samples of coal rock and other collected samples are all collected at the fresh working face of the coal mine in different mining areas at the basin margin. In order to make the samples more representative, the formation age of coal seams, the degree of coal metamorphism and the types of coal rocks 
Fig. 2 Comprehensive histogram of Jurassic strata in Junggar Basin, NW China

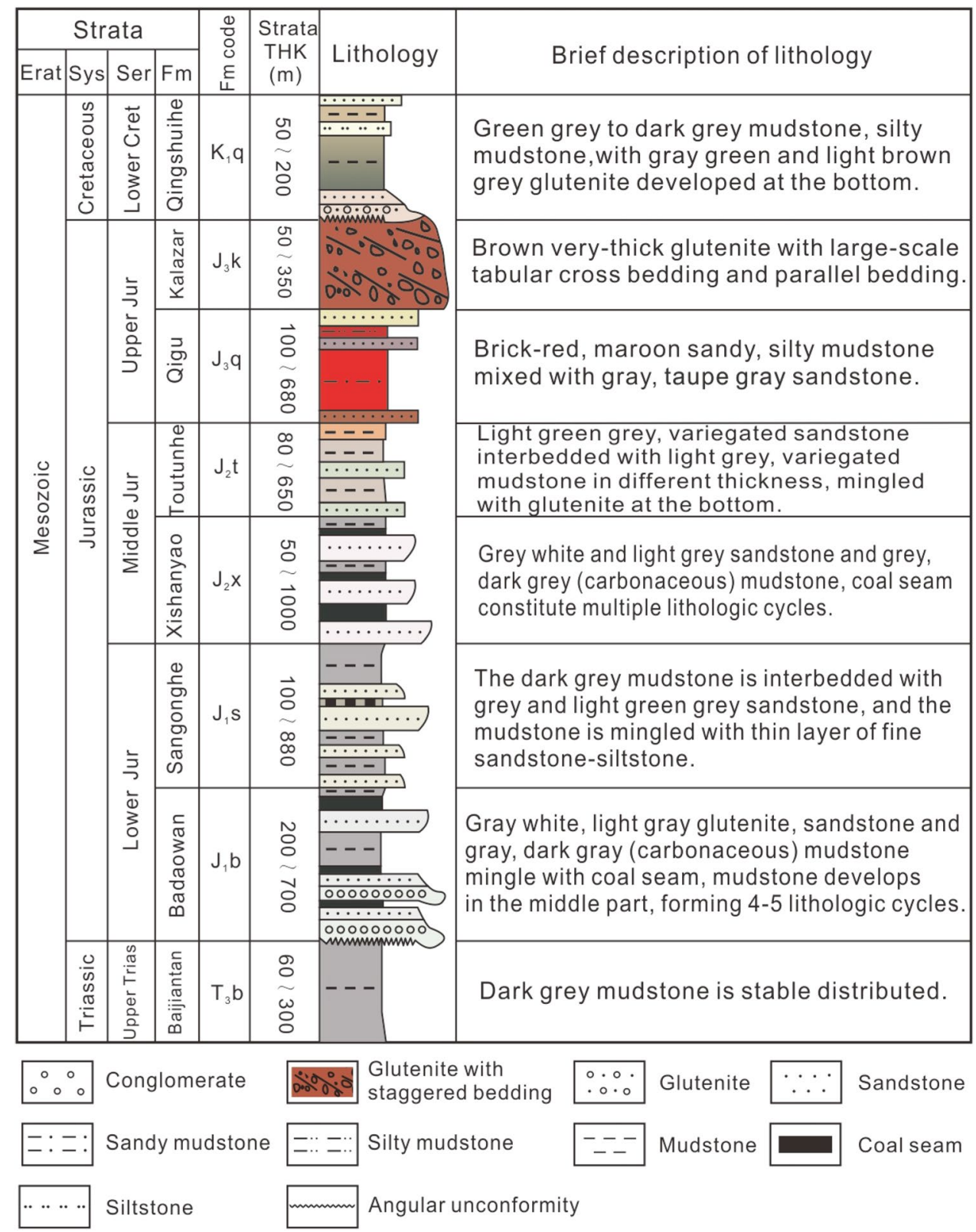

are fully considered in the sampling, and the samples are taken as far as possible in and near the coal-accumulating center of the basin (Figs. 3, 4).

\section{Research methods}

Based on geological survey and coal profile observation and sampling, this paper uses the methods of polished sections, thin sections, fluorescence microscope, common microscope observation and image analysis to research coal reservoir micro-area and uses the techniques of specific surface area measurement, mercury injection experiment, porosity-permeability joint tester, low temperature nitrogen adsorption and methane isothermal adsorption experiment and method of mathematical statistics fitting to study coal reservoir physical parameters. Thus, it is expected to reach a comprehensive understanding as far as possible through the combination of field investigation and indoor analysis, macro-profile and micro-microscope observation, various means of testing and experimental, combined with the previous data collection and analysis. The details are as follows:

(1) Study on coal reservoir distribution

The methods of field geological survey, seismic and geological data collection as well as indoor mapping are adopted. 
Table 1 Sampling statistics of low-rank coal reservoir in Junggar Basin, NW China

\begin{tabular}{|c|c|c|c|}
\hline No. & Sample and analysis content & Sample quantity (block/piece) & Test and analysis organization \\
\hline 1 & Coal specimen & 100 , weight is about $260 \mathrm{~kg}$ & \\
\hline 2 & Polished and thin sections & $\begin{array}{l}13 \text { polished sections of powder coal, } \\
\text { block coal and coal thin sections, } \\
\text { respectively }\end{array}$ & $\begin{array}{l}\text { Laboratory of energy and environment, China University of } \\
\text { Geosciences (Beijing) }\end{array}$ \\
\hline 3 & Analysis of coal macerals & 13 & Coal Geology Laboratory, Beijing Campus of China University \\
\hline 4 & Vitrinite reflectance measurement & 13 & of mining and technology \\
\hline 5 & $\begin{array}{l}\text { Quantitative statistics of microf- } \\
\text { racture and porosity }\end{array}$ & 23 for inspection, 41 for description & \\
\hline 6 & Porosity analysis & $\begin{array}{l}11 \text { for mercury injection and low } \\
\text { temperature liquid nitrogen } \\
\text { adsorption analysis }\end{array}$ & $\begin{array}{l}\text { Reservoir physical property Lab, Langfang branch of Research } \\
\text { Institute of Petroleum Exploration\& Development }\end{array}$ \\
\hline 7 & Permeability analysis & 11 & \\
\hline 8 & Adsorption/desorption experiment & 7 & \\
\hline
\end{tabular}

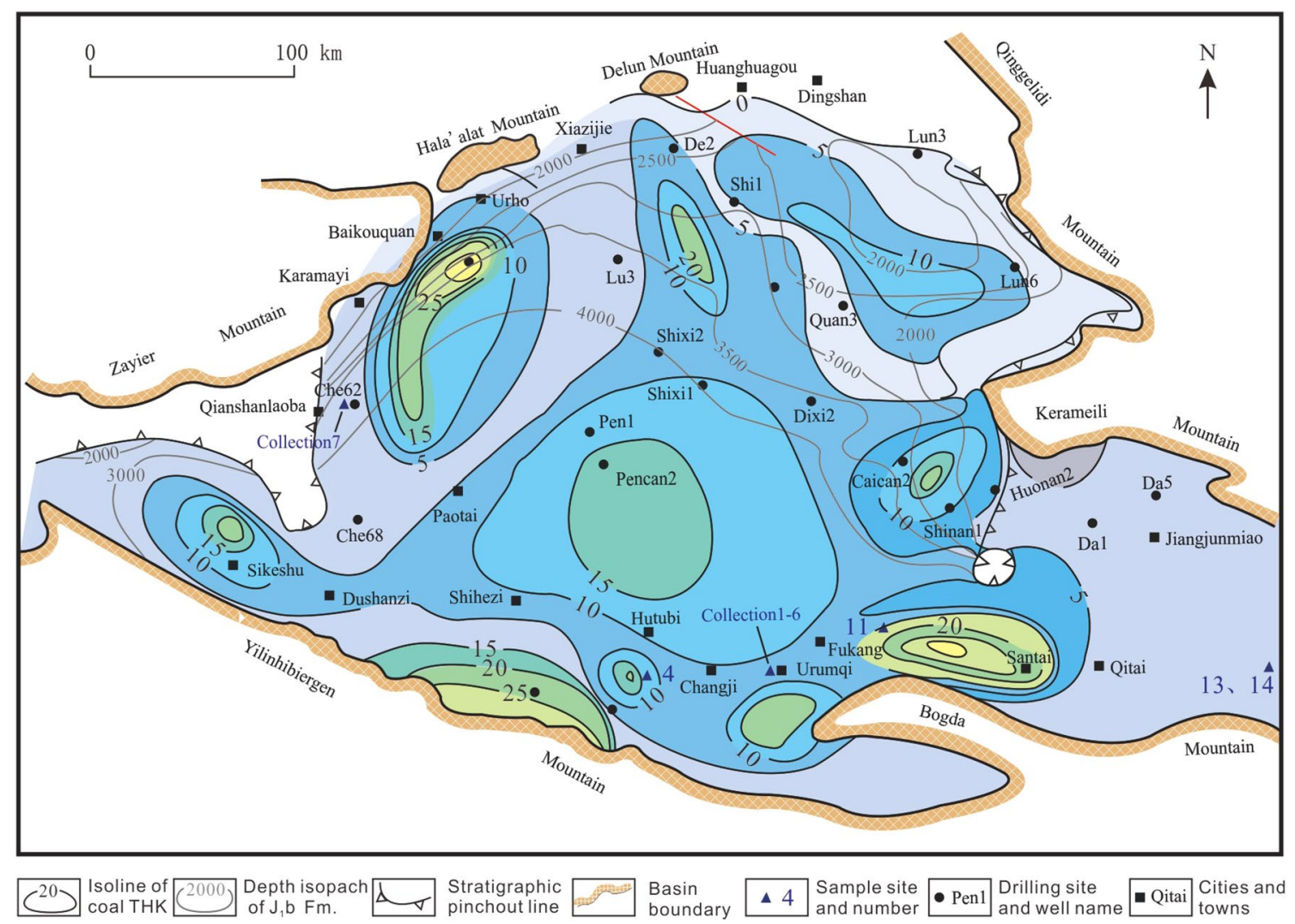

Fig. 3 Contour of thickness and buried depth of Badaowan Fm. coal reservoir in Junggar Basin (Unit in meter)

(2) Study on pore and fracture system of coal reservoir

The methods mainly included the observation of mine, specimen and polished sections of lump coal, the statistics of transmitted light, reflected white light and reflected fluorescence under the microscope, combined with mercury porosimetry, porosity-permeability joint tester, isothermal adsorption instrument, etc.
As for the study on fracture system of coal reservoir, because the fractures with different lengths of coal polished sections are completely filled with gum, under the fluorescence microscope, all kinds of fractures can be clearly identified and counted with the help of gum. The method is as follows: firstly, mix the broken rosin and paraffin into the basin according to a certain proportion; then burn them with fire, put the coal block into the basin, burn them to $12 \mathrm{~h}$, 


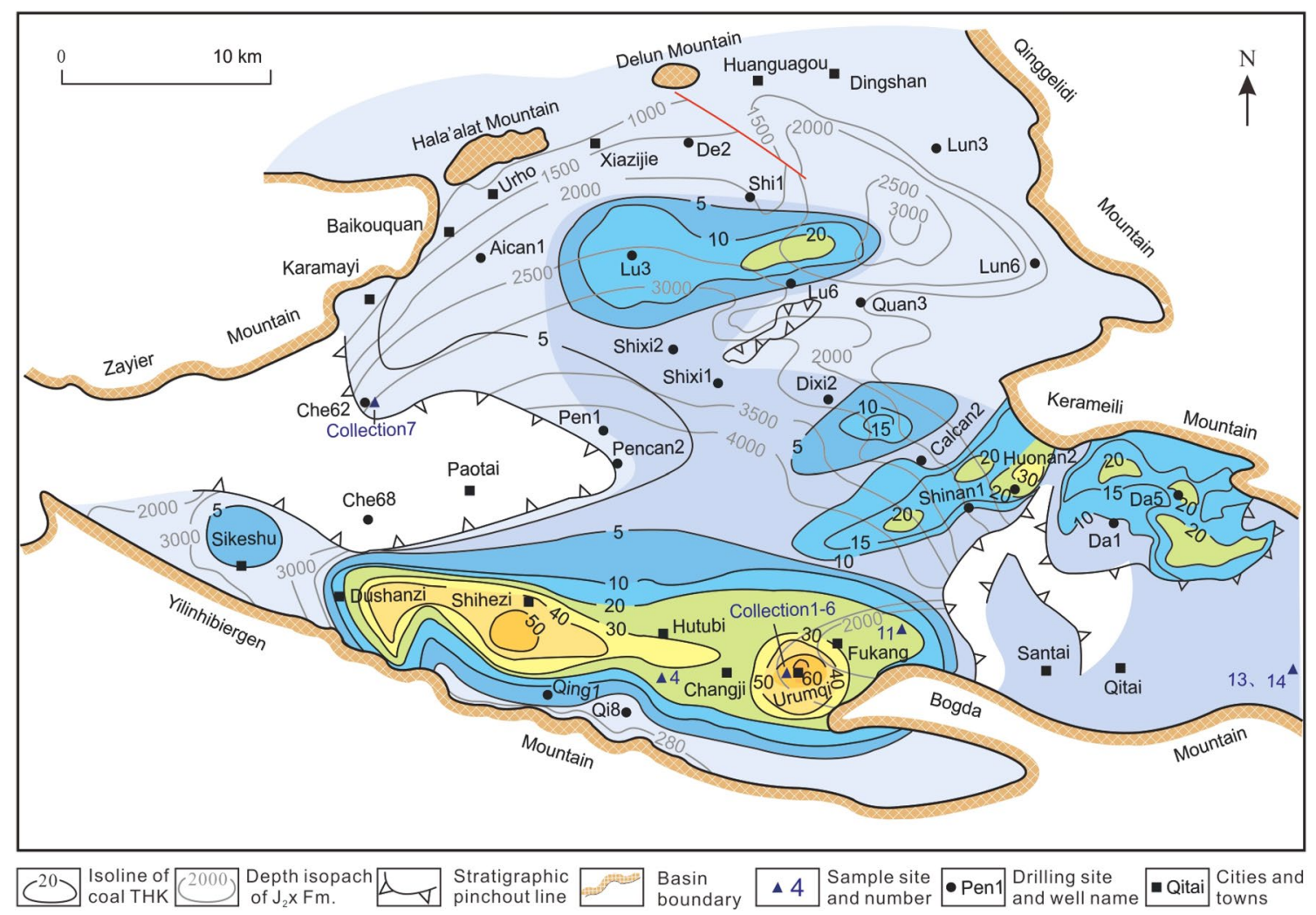

Fig. 4 Contour of thickness and buried depth of Xishanyao Fm. coal reservoir in Junggar Basin (Unit in meter)

take out the sample and cool it and then make them into coal polished sections of $30 \times 30 \mathrm{~mm}$. Under 50 times of fluorescence microscope, the polished sections of coal rock are divided into 9 micro-areas of $10 \times 10 \mathrm{~mm}$, and then the cracks in each micro-area are counted.

The pore system of coal reservoir is studied by methods of mercury injection and low temperature liquid nitrogen adsorption. Mercury injection experiment used the automatic mercury porosimeter of AutoPore IV-9410 type, which produced by Micromeritics Instrument Company of the USA. The working pressure of the instrument is 0.0035 to $206.843 \mathrm{MPa}$, the resolution is $0.1 \mathrm{~mm}^{3}$, the volume of the powder expander is $5.1669 \mathrm{~cm}^{3}$, and the lower limit of measurement is the pore diameter of $7.2 \mathrm{~nm}$. The working mode is computer program-controlled point measurement, in which 36 pressure points are selected in the high-pressure section $(0.1665 \leq P \leq 206.843 \mathrm{MPa})$, each point has a stable time of $2 \mathrm{~S}$, and the test amount of each sample is about 39 .

The method is to crush the selected pure coal sample to about $2 \mathrm{~mm}$ and eliminate the influence of mineral impurity, artificial fracture and structural fracture on the determination as much as possible. Put the sample in the oven before operation, dry it for $12 \mathrm{~h}$ under the condition of $70-80{ }^{\circ} \mathrm{C}$, and then put it into the expander to vacuumize it to $P<6.67 \mathrm{~Pa}$ for testing at room temperature of $8{ }^{\circ} \mathrm{C}$.
As for the study on pore type and distribution of coal reservoir, the specific surface area and pore size distribution are measured by low temperature nitrogen adsorption method. The instrument used is specific surface and pore size distribution instrument of ASAP2000 type. The range of pore size measured is 0.3 to $80 \mathrm{~nm}$.

\section{(3) Study on adsorption and desorption of coal reservoir}

Eleven coal samples were collected to carry out methane isotherm adsorption experiment of coal reservoirs. The experimental method is as follows: before the experiment, firstly crush 400 to $500 \mathrm{~g}$ sample to pieces with particle size less than $20 \mathrm{~mm}$, use quartering method to shrink, then put it into ball grinding tank for crushing and use 60 mesh and 80 mesh copper sieves for screening. The prepared coal samples were treated with balanced water, and then the moisture balanced coal samples were put into adsorption tank to simulate the conditions of underground reservoir to carry out methane isothermal adsorption/desorption experiment. The experimental apparatus was the Model IS-100 isothermal adsorption/desorption analyzer of Terratek Company, USA. The experimental temperature is $35^{\circ} \mathrm{C}$, the maximum initial pressure is 12.33 to $14 \mathrm{MPa}$, the experimental gas source is high-pressure $\mathrm{CH}_{4}$ gas, and the concentration of methane 
gas is $99.999 \%$. The testing items include the coal porosity, specific surface, macerals of coal rock, coal quality and vitrinite reflectance, Langmuir volume and Langmuir pressure (respectively, abbreviated as $V_{\mathrm{L}}$ and $P_{\mathrm{L}}$ ), etc.

The volume method is used to describe the adsorption characteristics during the experiment. At least six experimental points should be evenly selected within the experimental pressure range, and the experimental pressure should be increased in turn. The adsorption capacity of the sample under different pressure should be measured, and the adsorption capacity of the sample per unit mass corresponding to each equilibrium pressure should be calculated.

Desorption is the reverse reaction of adsorption. After the methane adsorption measurement by adsorption method and all test records are completed, operate in reverse direction, slowly open the shut-off valve of the adsorption tank and gradually reduce the pressure in turn until the methane pressure in the adsorption tank is close to the equilibrium pressure at the first point of the adsorption method. At least seven test points shall be evenly selected within the experimental pressure range, so as to obtain the desorption capacity of each pressure point. The experimental results were treated according to Langmuir equation, the Langmuir adsorption constant and Langmuir pressure constant were calculated, and finally the adsorption isotherm curve was obtained. Langmuir equation is as follows:

$V=\frac{V_{\mathrm{L}} P}{P+P_{\mathrm{L}}}=\frac{V_{\mathrm{L}}}{1+k}$

where $V$ is the experimental pressure. $V_{\mathrm{L}}$ is the Langmuir volume, which represents the maximum adsorption capacity, that is, the adsorption capacity when the coal adsorption methane reaches saturation at a given temperature, also known as "saturated adsorption capacity," whose size reflects the strength of the adsorption capacity for methane. $P$ is the experimental pressure. $P_{\mathrm{L}}$ is the Langmuir pressure, which is the corresponding pressure when the adsorption capacity reaches $50 \%$ of the maximum adsorption capacity, whose size reflects the difficulty degree of gas desorption. $K$ is the adsorption coefficient or adsorption constant, $K=P_{\mathrm{L}} / P$, which is related to the characteristics of adsorbent and represents the ability of solid to adsorb gas.

\section{(4) Study on gas-bearing property of coal reservoir}

The gas content of coal reservoirs is often evaluated with measured gas content, maximum adsorption capacity, methane concentration and gas saturation, which is the important basis of CBM resource evaluation. To ensure the reliability and objectivity of the data and conclusions, we try to use the measured data and experimental data to calculate and to count the data from the weathering zone of CBM to the maximum exploration depth $(<2000 \mathrm{~m})$. For the areas with few or lack of measured data, we calculate according to the gas emission, gas gradient, or mathematical statistics fitting method and gas gradient method.

(5) Evaluation of CBM resources Potential and grading favorable blocks

The project "evaluation of CBM resources in northwest China" participated by the authors used the Volume Method to evaluate the shallow CBM resources (Yang et al. 2005). The data of shallow CBM resources above $2000 \mathrm{~m}$ from Cui et al. (2007) are quoted.

Based on the measured values of Langmuir volume and some fitted values of the coal reservoir in Junggar Basin, combined with methane adsorption capacity and distribution of coal reservoir, grading evaluation of favorable blocks is carried out.

\section{Results: characteristics of low-rank coal reservoir}

\section{Distribution characteristics of low-rank coal reservoir}

The Badaowan Fm. coal measures form several small coalaccumulating centers in the Junggar Basin (Fig. 3). There are the best coal-bearing property in the coal mine along Urumqi to Fukang to Santai at the east of southern margin and in the downhole formation along Karamay to Baikouquan to Urho at the northwestern margin. The thickness of the coalbeds is generally 5-20 m, and the thickness of single layer can be more than $15 \mathrm{~m}$. The coal reservoir development became better from north to southeast.

Xishanyao Fm. has a good coal-bearing property, stable distribution, wide range and multiple layers (5-30 layers) of coalbeds, compared to Badaowan Fm., the coal-rich zone in the Xishanyao Fm. shifts to the west apparently, and the coal-accumulating center also shifts to the west and broadens, with the major coal-accumulating center in the Urumqi-Dushanzi area at the southern margin (Fig. 4). The coalbeds are 10-30 m thick in general, mostly thick or very thick recoverable ones (with single coalbed thickness of 40-60 $\mathrm{m}$ and cumulative thickness of $174-182 \mathrm{~m}$ at the southern margin).

Different color shadows in Figs. 3 and 4 are mainly used to represent the distribution of coal-accumulating centers. The darker and brighter the color shadow, the thicker the coal reservoir. From light color to dark color shade, it means that the thickness of coal seam increases gradually. The thickness data on the drawing also show this change.

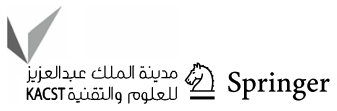


According to the statistics (Wang and Zhang 2002; Chen et al. 2003; Yu et al. 2006; Yang et al. 2005), the Middle-Lower Jurassic coal reservoir contains 9-53 recoverable coal layers of 20.9-202.8 m thick in total, with a coalbearing coefficient of 1.4-4.6\%; the coal is mainly low ash, low sulfur and low rank. The coal reservoir has Ro from 0.40 to $1.01 \%$, mostly 0.45 to $0.8 \%$; longitudinally, Ro is small in the coal mine and surface section but high in the downhole, and on the plane Ro is higher in the south than north. The coal-rich zone lies in the lacustrine to delta facies, and the major coalbeds are well connected, which provide good conditions for the accumulation of CBM.

Burial depth is one of the most important factors to evaluate the potential of CBM resources. Under the current economic and technological conditions, it is more appropriate to exploit CBM at the depth of less than $2000 \mathrm{~m}$, while it is more difficult to exploit CBM at the depth of more than $2000 \mathrm{~m}$. Therefore, the lower limit of economic and technological mining depth for CBM is generally defined as $2000 \mathrm{~m}$. The coal seams in southern Junggar Basin are buried 400 to $1200 \mathrm{~m}$ and rapidly deepen from the southern margin of the basin to the basin (Figs. 3, 4). The stratum occurrence is steep, and the dip angle in Miquan-Fukang-Dahuangshan area can exceed 45 degrees. The buried depth of coal seams in eastern Junggar Basin is shallower than $800 \mathrm{~m}$, and its occurrence is gentle (Sun et al. 2012).Generally speaking, the buried depth of Middle-Lower Jurassic Badaowan Fm. and Xishanyao Fm. is less than $1500 \mathrm{~m}$ in the margin of Junggar Basin, which is suitable for CBM exploration and development.

\section{Physical property of low-rank coal reservoir}

According to the observation statistics of coal mine profile and microscope, the macroscopic and microscopic fractures of Jurassic coal reservoir in Junggar Basin are developed. The macro- and micro-fractures are mostly reticulated and intersected, with good opening degree and connectivity, forming a good channel for CBM migration and accumulation. There are two kinds of microcracks, one is the microcracks with width less than $5 \mu \mathrm{m}$ and length less than $300 \mu \mathrm{m}$, accounting for 35.7-64.9\%, with short extension and discontinuity; the other is the microcracks with width less than $5 \mu \mathrm{m}$ and length $300 \mu \mathrm{m}$ to $1 \mathrm{~mm}$, accounting for $20.5 \%-55.6 \%$, with intermittent extension. A small number of microcracks with width $\geq 5 \mu \mathrm{m}$, length of $1-10 \mathrm{~mm}$ and continuous length account for 3.9-14.2\%; microcracks with width $>5 \mu \mathrm{m}$ and length $>10 \mathrm{~mm}$ only account for $0.8-4.3 \%$.

The mercury injection data demonstrate that the pores in the low-rank coal reservoirs across the Junggar Basin are largely small to micro-pores $(<100 \mathrm{~nm})$ and macropores. Bimodal pores structure of Badaowan Fm. coal reservoir is the most obvious, the proportion of big pore and small-micropore is almost the same, close to 50\%, while that of Xishanyao Fm. coal reservoir is dominated by small to micropore, up to $50-85 \%$. The proportion of macropores to mesopores is relatively high, which provides a space for the occurrence of free gas and adsorbed gas. The porosity of mercury injection method is generally $3.25-27.4 \%$, with an average of $9.4 \%$; the median radius is $0.0077-1.1359 \mu \mathrm{m}$, with an average of $0.2415 \mu \mathrm{m}$. The data of porosity-permeability joint tester show that the porosity of coal reservoir is between $5.6 \%$ and $20.8 \%$, with an average of $10.51 \%$, and $20.8 \%$ with (micro) fractures.

The permeability of Jurassic coal reservoir changes greatly because of macro- and micro-fractures. For the coal reservoir without (micro) fracture, the permeability is 0.321-6.17 $\mathrm{mD}$; for the coal reservoir with (micro) fracture, the permeability ranges from $8.67-11.7 \mathrm{mD}$, up to $1383 \mathrm{mD}$ individually (Table 2). Generally speaking, the permeability of dull coal is the lowest, from semi-dull coal to semibright coal to bright coal, its permeability tends to increase. According to the evaluation standard of coal reservoir, it should be a low to medium permeability reservoir, those with (micro) fractures can reach the level of high permeability reservoir, which is beneficial to the exploitation of CBM.

The low temperature nitrogen adsorption test shows that the specific surface of coal reservoir in this area is $0.171-9.734 \mathrm{~cm}^{2} / \mathrm{g}$, the total pore volume is $0.00098-0.01873 \mathrm{ml} / \mathrm{g}$, the average pore diameter is $8.89-11.57 \mathrm{~nm}$. There are mainly small pores and micropores, accounting for 48.93 to $61.71 \%$ and $10.29-48.33 \%$, respectively. The micro-pore structure parameters show that the pore-throat distribution of $\mathrm{J}_{1} \mathrm{~b}$ coal reservoir tends to normal distribution, showing obvious bimodal distribution of large pore and small to micropore. The pores of $\mathrm{J}_{2} \mathrm{x}$ coal reservoir are slightly larger, the throat is smaller, and the connectivity is not as good as $\mathrm{J}_{1} \mathrm{~b}$ coal reservoir.

On the whole, the $\mathrm{J}_{1} \mathrm{~b}$ coal reservoir has lower porosity than that of $\mathrm{J}_{2} \mathrm{x}$, but the average median radius of $\mathrm{J}_{1} \mathrm{~b}$ coal reservoir is much larger than that of $\mathrm{J}_{2} \mathrm{x}$ coal reservoir. It shows that $\mathrm{J}_{1} \mathrm{~b}$ coal reservoir is more favorable for the migration and exploitation of CBM, while $\mathrm{J}_{2} \mathrm{x}$ coal reservoir is more favorable for the adsorption and accumulation of CBM.

\section{Adsorption-desorption features of low-rank coal reservoir}

More than $90 \%$ of methane exists in adsorption state within the range of economic and effective mining depth. The adsorption/desorption performance of coal reservoirs has a significant impact on the gas-bearing property of coal reservoirs and the productivity of CBM wells (Sang et al. 2003; Fu et al. 2005; Zhang et al. 2002). 
Table 2 Physical property of coal reservoir by porosity-permeability joint tester in Junggar Basin

\begin{tabular}{|c|c|c|c|c|c|c|c|}
\hline Sample number & Sampling sites & Horizon & Coal lithotypes & Porosity (\%) & $\begin{array}{l}\text { Perme- } \\
\text { ability } \\
(\mathrm{mD})\end{array}$ & $\begin{array}{l}\text { Coal } \\
\text { rank Ro } \\
(\%)\end{array}$ & Remark \\
\hline 3 & Changji Liuhuanggou & $\mathrm{J}_{2} \mathrm{X}$ & Clarain & 7.2 & 1.73 & 0.54 & \\
\hline 4 & Changji Liuhuanggou & $\mathrm{J}_{2} \mathrm{x}$ & Clarain & 7 & 2.51 & 0.51 & \\
\hline FK1-2 & Fukang Sangonghe mine & $\mathrm{J}_{2} \mathrm{X}$ & Durain & 14.4 & 0.321 & 0.64 & \\
\hline FK2-2 & Fukang Sangonghe mine & $\mathrm{J}_{2} \mathrm{x}$ & Clarain and durain & 12.7 & 1.1 & 0.60 & \\
\hline STH1-2 & Santanghu coal mine & $\mathrm{J}_{2} \mathrm{X}$ & Semi-bright coal to clarodurite & 11.7 & 6.17 & 0.54 & \\
\hline ML1-2 & Mulei coal mine & $\mathrm{J}_{2} \mathrm{X}$ & Fat-gas coal & 20.8 & 8.67 & 0.58 & Microcracks \\
\hline BLQ1-2 & Balikun coal mine $23^{\#}$ well & $\begin{array}{l}\mathrm{J}_{1} \mathrm{~b} \text { upper } 4 \\
\text { coal meas- } \\
\text { ures }\end{array}$ & Gas coal (2\# coal) & 7.8 & 11.7 & 0.81 & Microcracks \\
\hline FK3-2 & Fukang Sangonghe mine & $\mathrm{J}_{1} \mathrm{~b}$ & Semi-bright coal & 5.6 & 2.3 & 0.61 & \\
\hline FK4-2 & Fukang Sangonghe mine & $\mathrm{J}_{1} \mathrm{~b}$ & Clarain & 7.4 & 1383 & 0.59 & Cracks \\
\hline
\end{tabular}

Experiments prove that the desorption isotherm of coal reservoir coincides with the adsorption isotherm, that is, desorption of coal reservoir is the reverse process of adsorption. Therefore, through the results of methane isothermal adsorption experiments and isotherm adsorption curves of the coal reservoir in Junggar Basin, we can analyze desorption properties, adsorption performance and CBM development performance of the coal reservoirs (Table 3, Fig. 5). The data of Fig. 5 are from the measured data of four selfcollected samples in Table 1, namely, 4, 11, 13 and 14.

\section{(1) Langmuir volume and CBM reservoir performance}

The Langmuir volume $\left(V_{\mathrm{L}}\right)$ refers to the saturated gas adsorption volume in the raw coal (theoretical adsorption volume), and the Langmuir volume from the adsorption isothermal line represents the maximum gas volume at the in situ coalbed state, namely the maximum CBM volume in the coal reservoir. On the basis of previous research, the paper tested the adsorption isothermal parameter, Langmuir volume $\left(V_{\mathrm{L}}\right)$, by the experiments and then classified the coal reservoirs into five types, i.e., the extremely methane-rich coalbed $\left(V_{\mathrm{L}} \geq 20 \mathrm{~m}^{3} / \mathrm{t}\right)$, methane-rich coalbed $\left(V_{\mathrm{L}}\right.$ is $\left.15-20 \mathrm{~m}^{3} / \mathrm{t}\right)$, relatively methane-rich coalbed $\left(V_{\mathrm{L}}=8-15 \mathrm{~m}^{3} / \mathrm{t}\right)$, methane-bearing coalbed $\left(V_{\mathrm{L}}=4-8 \mathrm{~m}^{3} / \mathrm{t}\right)$, and methane-poor coalbed $\left(V_{\mathrm{L}}<4 \mathrm{~m}^{3} / \mathrm{t}\right)$, to make the discussion on its gas storage performance.

The isothermal adsorption curve and characteristics of methane in coal reservoir are shown in Fig. 4. The experimental data show that the total raw coal $V_{\mathrm{L}}$ of Jurassic coal is from 4.96 to $16.29 \mathrm{~m}^{3} / \mathrm{t}$ and $10.64 \mathrm{~m}^{3} / \mathrm{t}$ on average; the total combustible $V_{\mathrm{L}}$ is from 5.65 to $31.87 \mathrm{~m}^{3} / \mathrm{t}$ and $17.97 \mathrm{~m}^{3} / \mathrm{t}$ on average, indicating the coal reservoirs have high gas storage capacity, and the gas enrichment degree in the coalbed can be quite high when other conditions are suitable.
In terms of horizon, the combustible $V_{\mathrm{L}}$ of $\mathrm{J}_{2} \mathrm{x}$ coal reservoir ranges from 5.65 to $31.87 \mathrm{~m}^{3} / \mathrm{t}$ and averages $20.07 \mathrm{~m}^{3} / \mathrm{t}$; the combustible $V_{\mathrm{L}}$ of $\mathrm{J}_{1} \mathrm{~b}$ coal reservoir ranges from 5.94 to $18.06 \mathrm{~m}^{3} / \mathrm{t}$ and averages $12.38 \mathrm{~m}^{3} / \mathrm{t}$, indicating the $\mathrm{J}_{2} \mathrm{x} V_{\mathrm{L}}$ is larger than $\mathrm{J}_{1} \mathrm{~b} V_{\mathrm{L}}$, thus $\mathrm{J}_{2} \mathrm{x}$ coalbed has stronger methane adsorption capacity and better reservoir quality than $\mathrm{J}_{1} \mathrm{~b}$ coalbed.

In terms of region, the coalbeds in the Fukang area at the southern basin margin have a higher adsorption capacity, the theoretical maximum adsorption volume of raw coal sample with balanced water can amount to $14.14 \mathrm{~m}^{3} / \mathrm{t}$, reaching the level of relatively methane-rich coalbed, while the coalbeds in Liuhuanggou belt of Changji prefecture with theoretical maximum adsorption volume of balanced water raw coal sample of $7.16 \mathrm{~m}^{3} / \mathrm{t}$, reach the level of methanebearing coalbeds. If it is converted into moisture-free basis CBM (methane + heavy hydrocarbon) content, its adsorption capacity will be higher. In the eastern basin, coalbeds in the Balikun coal mine have higher adsorption capacity and stronger gas storage capacity. It is predicted that the coalbeds in Changji-Urumqi-Fukang areas in the southern basin and Cainan-Balikun coalmine regions in the eastern basin all can reach the relatively to extremely methane-rich level, with strong gas adsorption and accumulation capacity as well as high development potential.

\section{(2) Langmuir pressure and CBM development potential}

The Langmuir pressure $\left(\mathrm{P}_{\mathrm{L}}\right)$ refers to the pressure value corresponding to $50 \%$ of maximum adsorption volume $\left(V_{\mathrm{L}}\right.$ in case of $50 \%$ adsorption volume), or the pressure value corresponding to the adsorption volume at $50 \% V_{\mathrm{L}}$, which reflects the difficulty of CBM desorption and recovery. Generally speaking, if the $V_{\mathrm{L}}$ is high, the $\mathrm{P}_{\mathrm{L}}$ greater than $3 \mathrm{MPa}$ implies high production. 


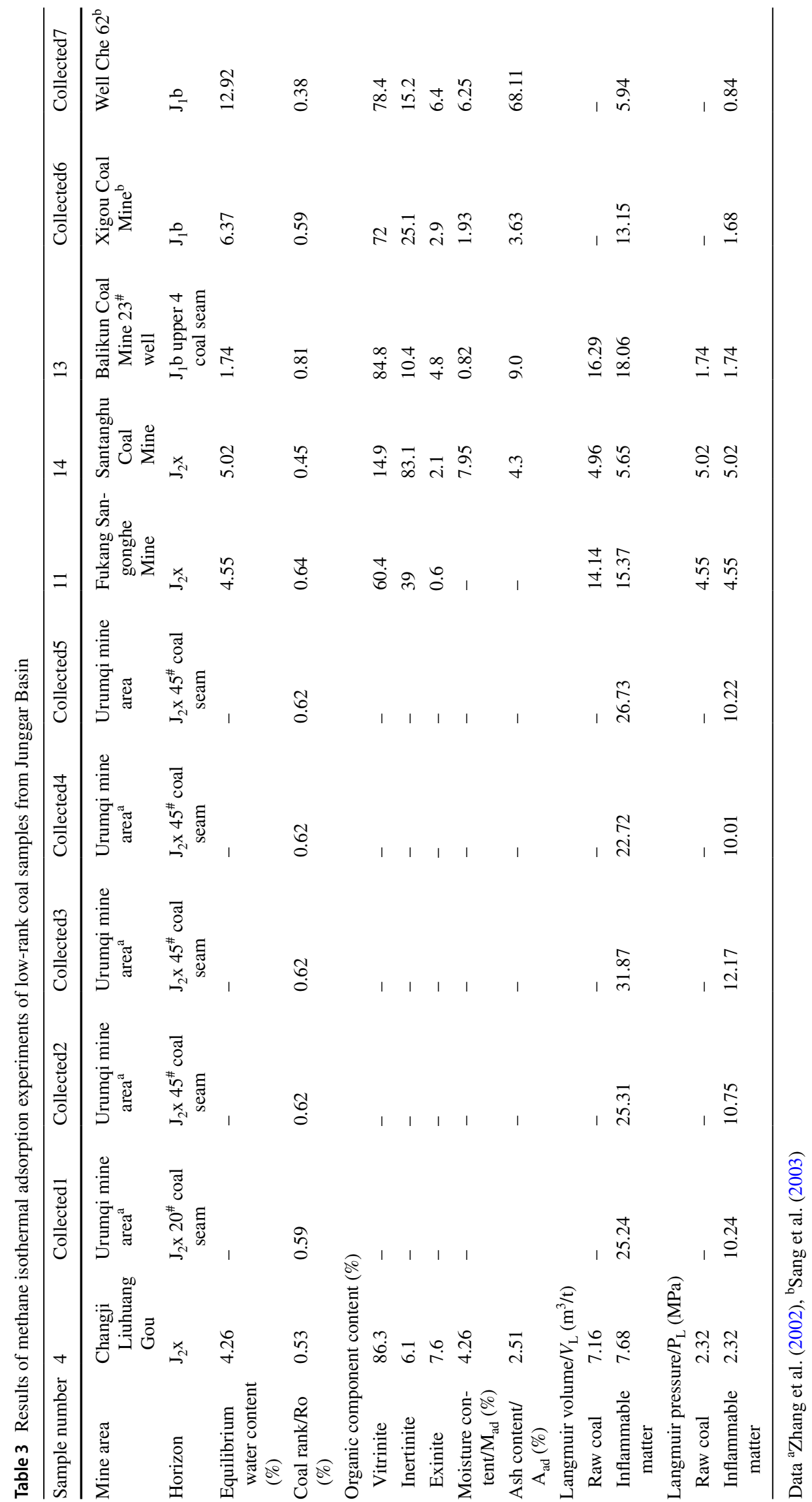



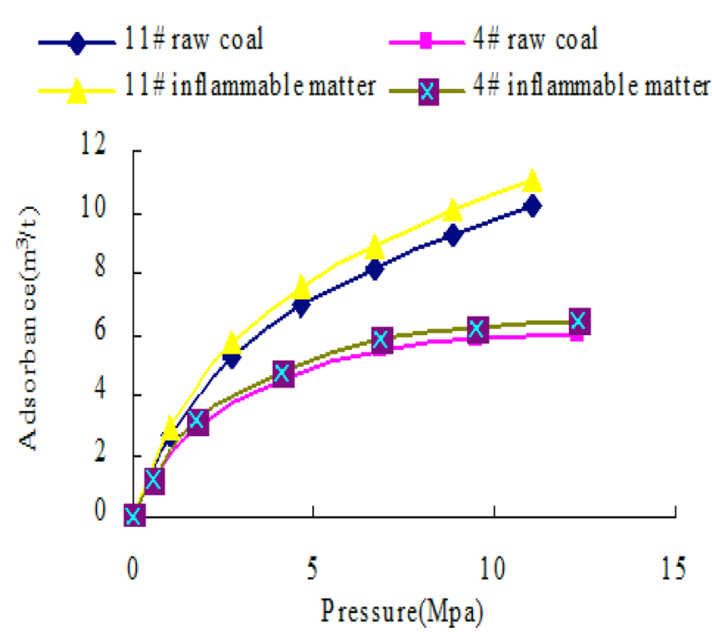

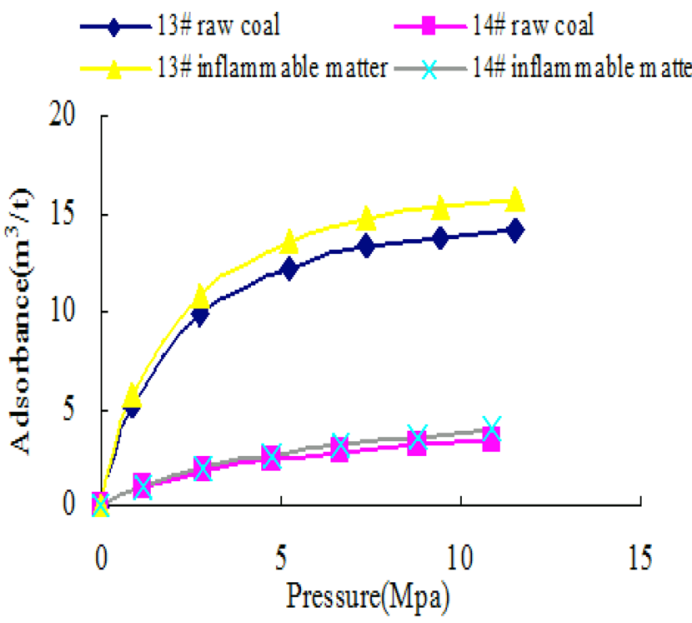

Fig. 5 Methane isothermal adsorption curve of low-rank coal reservoirs in Junggar Basin, NW China

From the experimental results, the $P_{\mathrm{L}}$ of combustible coal samples in the Junggar Basin is generally medium-relatively high, 0.84-12.17 MPa, and 6.32 MPa on average. For specific horizons, the Xishanyao Fm. has $P_{\mathrm{L}}$ of combustible coal sample between 2.32 and $12.17 \mathrm{MPa}$ and $8.16 \mathrm{MPa}$ on average; for Badaowan Fm., the corresponding values are from 0.84 to $1.74 \mathrm{MPa}$ and $1.42 \mathrm{MPa}$ on average. The Xishanyao Fm. coal reservoir has higher $P_{\mathrm{L}}$ than Badaowan Fm., so generally $\mathrm{J}_{2} \mathrm{x}$ coalbed has higher critical desorption pressure and lower pressure difference between initial coal seam and critical desorption. The $\mathrm{J}_{2} \mathrm{x}$ has stronger methane desorption capacity than $\mathrm{J}_{1} \mathrm{~b}$, making the development of its CBM easier.

In terms of region, the area along Urumqi at the southern margin presents the highest Langmuir pressure $(10.01-12.17 \mathrm{MPa})$ and largest $V_{\mathrm{L}}\left(22.72-31.87 \mathrm{~m}^{3} / \mathrm{t}\right)$, and the area along Fukang also presents large $V_{\mathrm{L}}$, where the CBM would easily desorb along with the pressure drop. In the area along the Santanghu-Balikun in the eastern basin, although the surface coal sample has fairly high $V_{\mathrm{L}}$ but the lowest $\mathrm{P}_{\mathrm{L}}$, demonstrating that the CBM is most difficult to desorb, which is unfavorable for CBM recovery. Apparently, the CBM can reach medium to high productivity in Urumqi-Fukang area, while moderate to low productivity in the other areas.

\section{Gas-bearing property of low-rank coal reservoir}

At present, there are few special CBM exploration wells in this area, and the measured gas content data are scarce. The gas-bearing property of coal reservoir can be comprehensively evaluated by combining the measured gas content, maximum adsorption capacity, methane concentration and gas saturation.
PetroChina Xinjiang Oilfield Company has found CBM or its indication in Baijiahai uplift and Qigu oilfield from 1996 to 2006. The CBM showing are commonly observed in the $\mathrm{J}_{2} \mathrm{X}$ coalbed of coal mines of Xinjiang Coalfield Geology Bureau from 1983 to 2016, and the CBM content is $2-4 \mathrm{~m}^{3} / \mathrm{t}$ and reaches up to $9.2 \mathrm{~m}^{3} / \mathrm{t}$ in some of the Urumqi-Baiyanghe coal mine at the east of southern margin. The daily gas drainage reaches $2000 \mathrm{~m}^{3}$ in the Dahuangshan coal mine.

As for general areas, the measured average gas content of $\mathrm{J}_{2} \mathrm{X}$ and $\mathrm{J}_{1} \mathrm{~b}$ coal reservoirs is $4.2-6 \mathrm{~m}^{3} / \mathrm{t}$ and $2.0-6.4 \mathrm{~m}^{3} / \mathrm{t}$, respectively, and mostly is less than $2 \mathrm{~m}^{3} / \mathrm{t}$. As for the southern margin of Junggar Basin, its gas content of coal seams is higher, distributed between 2 and $15 \mathrm{~m}^{3} / \mathrm{t}$. The tested dry airbased gas content of Xishanyao Fm. in Urumqi to Changji area ranges from 2.70 to $8.60 \mathrm{~m}^{3} / \mathrm{t}$ and averages $6.28 \mathrm{~m}^{3} / \mathrm{t}$. On the plane, the CBM adsorption content tends to increase from west to east, and the gas content of the Xishanyao Fm. in the eastern and central parts of the southern margin is relatively high ( $\mathrm{Li}$ et al. 2016). The gas adsorption content in the Urumqi mine is the highest, reaching $8.60 \mathrm{~m}^{3} / \mathrm{t}(\mathrm{Jia}$ et al. 2015).

The theoretical gas content of $1000 \mathrm{~m}$ buried depth is $6.25-13.87 \mathrm{~m}^{3} / \mathrm{t}$ in $\mathrm{J}_{2} \mathrm{x}$ coalbed and $5.52-15.6 \mathrm{~m}^{3} / \mathrm{t}$ in $\mathrm{J}_{1} \mathrm{~b}$ coalbed predicted by using the third-order polynomial fitting empirical formula and graphic method. Jia et al. (2015) estimated by the gas equation the total gas content in coal group B (main coal seam) of Xishanyao Fm. as 2.85 to $8.94 \mathrm{~m}^{3} / \mathrm{t}$, with an average of $6.12 \mathrm{~m}^{3} / \mathrm{t}$. Among them, free gas accounts for $2.89-5.14 \%$ of the total gas content and $3.90 \%$ on average. Chen et al. (2015) simulated that the free gas content gradually exceeds the adsorbed gas content with the increase in depth and water saturation for the deep coal reservoir in Junggar Basin. 
The shallow coal reservoirs in the Junggar Basin are mostly undersaturated, and the theoretical gas saturation of Jurassic coal reservoir calculated with measured data is about 30-50\%. Sang et al. (2005) calculated the gas saturation with gas-bearing gradient method at around 70-100\% at the burial depth 800 to $1000 \mathrm{~m}$ in the southern and eastern Junggar Basin. Deep down, the coalbeds tend to increase in gas saturation, turning to saturated and oversaturated reservoirs gradually.

\section{Resource property of low-rank CBM}

Comparing the Junggar Basin with the Powder River Basin in the USA, it is found that the coal-bearing properties, sedimentary and hydrogeological conditions of the two basins are similar. Especially, they belong to low metamorphic lignite-subbituminous coal, which have good coal-bearing properties and have certain comparability of CBM pools formation. Although the content of CBM in low-rank coal is not very high, a large proportion of gas can still be desorbed and produced during drainage and pressure reduction due to the strong gas desorption capacity. At the same time, because of large thickness and good permeability of the coal seam, the surface extraction has relatively large gas production potential. Therefore, even though the CBM content in Junggar Basin is a little low, the CBM pool can still be formed and has the potential of development as long as the reservoir-forming conditions are suitable.

According to the results of CBM resource evaluation using volumetric method, Junggar Basin possesses rich CBM resources, and the CBM resources less than $1500 \mathrm{~m}$ and $2000 \mathrm{~m}$ depth are $3.87 \times 10^{12} \mathrm{~m}^{3}$ and $3.92 \times 10^{12} \mathrm{~m}^{3}$, respectively (Yang et al. 2005; Cui et al. 2007). They account for $10.58 \%$ and $10.72 \%$ of the total CBM resources in China, respectively. Among them, most of resources belong to lowrank CBM (Wang et al. 2016), accounting for $37.57 \%$ and $38.06 \%$ of China's low-rank CBM resources, respectively. Therefore, the potential of low-rank CBM resources in Junggar Basin is great.

\section{Discussion: potential evaluation of low-rank CBM}

\section{Main-controlling factors of adsorption performance of coal reservoir and mathematical statistics fitting}

It should be pointed out that the Langmuir volume reflects the maximum adsorption capacity of coal, under a certain pressure the coal with larger Langmuir volume does not necessarily have larger adsorption volume; under a certain pressure, especially in the low pressure area, the adsorption volume of coal is related to not only the Langmuir volume but also the Langmuir pressure, the smaller the Langmuir pressure, the greater the adsorption volume is, otherwise the smaller the adsorption volume is.

It can be seen from Fig. 4 that the coalbed with larger Langmuir pressure has small bending degree on isothermal adsorption curve, suggesting the adsorption volume is relatively small in the low pressure range and the adsorption volume increment increases with the pressure rise in the high pressure range, while the coalbed with small Langmuir pressure has larger bending degree of isothermal adsorption curve, indicating its adsorption volume is relatively large in the low pressure range and its adsorption increment decreases with the pressure rise in the high pressure range. In different coalbeds with approximately same desorption pressure, the methane desorbs more easily from the coalbed with smaller bending degree on the absorption isothermal curve, namely the recovered gas volume from coalbed with smaller bending degree would be more than that from coalbed with greater bending degree.

Under the isothermal condition, the adsorption volume is positively related to the reservoir pressure. With the rise of pressure, the adsorption volume increases (namely the adsorption capacity of coal on the methane strengthens), when the pressure ranges from 0 to $1 \mathrm{MPa}$, except a few samples, the adsorption volume of most samples shows linear increase in large slope with the rise of pressure, afterward the increase rate gradually declines till zero when the coal adsorption reaches the saturated state.

Relevant experiments show that adsorption capacity of coal is significantly affected by coal metamorphism, temperature, moisture content and pore size (Zhang and Yang 1999; Fu et al. 2005). The measured and collected methane isothermal adsorption data of coal samples in this area are plotted to form figures, and the high-order polynomial fitting, power fitting, logarithmic fitting, linear fitting and exponential fitting are carried out, respectively, by mathematical statistics fitting method. The results indicate that the relationship between methane isothermal adsorption value and coal grade Ro has the highest fitting degree and the largest correlation coefficient by the third-order polynomial (Yu et al. 2008). Zhang (2016) also found that the metamorphism degree of coal has an important role in controlling the adsorption performance of coal; Langmuir volume $\left(V_{\mathrm{L}}\right)$ of coals in the eastern Junggar region increases significantly with the increase in reflectivity Ro (Fitness $R_{2}=0.78$ ). It can be seen that the Langmuir volume $\left(V_{\mathrm{L}}\right)$ increases with the increase in coal grade Ro.

The Langmuir volume (theoretical adsorption capacity) obtained from adsorption isotherm, that is, the saturated adsorption capacity of coal reservoir represents the maximum gas content of coal seam in situ and is also the maximum capacity of CBM. In order to study the gas-bearing property of coal reservoir in combination with the geological 
characteristics of the basin, this paper assumed the gas adsorption in the coal reservoir at saturate state, formation temperature at $35^{\circ} \mathrm{C}$, reservoir pressure as hydrostatic pressure at burial depth $1000 \mathrm{~m}(11.02 \mathrm{MPa})$. On the basis of the mathematical fitting of the relationship between $V_{\mathrm{L}}$ and Ro, combined with the relationship between water content of coal and $V_{\mathrm{L}}$ of coal reservoir, the empirical fitting formulas of higher-order polynomial, power, logarithm, linearity and exponent are established, respectively. These empirical formulas are used to calculate the fitting values of $V_{\mathrm{L}}$ at known measured points in Junggar Basin and compared with the measured values of $V_{\mathrm{L}}$. The results show that the deviation between the fitting value of Langmuir volume calculated by the empirical formula of third-order polynomial fitting (Formula is $V_{\mathrm{L}}=-1701.4 R_{\mathrm{o}}^{3}+2753.6 R_{\mathrm{o}}^{2}-1354.5 R_{\mathrm{o}}+210.6$ 6 ) and the measured value of Langmuir volume is the smallest, with the greatest correlation and the highest reliability. Based on this formula, under the circumstances of unknowing or lacking the measured value of $V_{\mathrm{L}}$ (methane isothermal adsorption capacity), the $V_{\mathrm{L}}$ fitting value of coal reservoirs in the main mining areas of the basin can be deduced by easily obtained Ro value; thus, we can further deduce the development potential of CBM in the basin.

The theoretical significance of mathematical statistics fitting method lies in: on the one hand, the isotherm adsorption experiments of coalbed methane are usually expensive, which results in high cost of obtaining Langmuir volume; on the other hand, data in low-degree exploration areas are often scarce and lack of regional representation. However, the relationship between the Langmuir volume $\left(V_{\mathrm{L}}\right)$ and the vitrinite reflectance (Ro) is established by mathematical statistics, which realizes the combination of isothermal adsorption experimental value and simulated values. Thus, the basis for trend judgment is more sufficient, which is conducive to promoting the research rhythm and accelerating the exploration process. The method can be used in the areas without drilling and lower exploration degree, having higher popularized value.

\section{Classification of gas-bearing blocks and evaluation of prospective blocks}

On the basis of real measured value and some fitting value of coal reservoir Langmuir volume, the Langmuir volume isopaches of Jurassic coal reservoirs in Junggar Basin were plotted (Figs. 6, 7).

According to the theoretical gas saturation of coal reservoirs and availably favorable gas content of CBM development, considering that the theoretical gas saturation of Jurassic coal reservoir calculated from measured data is generally about $30-50 \%$ and the favorable gas content for CBM exploitation, in combination with five types of coal reservoirs and methane adsorption capacity, the four classes of CBM blocks in the region can be divided to evaluate the development characteristics and potential of low-rank CBM:

Class I block/CBM-rich block Blocks with extremely methane-rich coalbeds with the Langmuir volume of more than $20 \mathrm{~m}^{3} / \mathrm{t}$. The CBM-rich blocks of Xishanyao Fm. are mainly distributed in the Cainan-Balikun mine in the eastern basin, where the coal reservoirs have strong absorption to methane; thus, the sites with trap can form valuable CBM pools.

Class II block/relatively CBM-rich block Blocks contain relatively methane-rich coalbeds with the $V_{\mathrm{L}}$ of $15-20 \mathrm{~m}^{3} / \mathrm{t}$. The relatively CBM-rich blocks of Xishanyao Fm. are mainly in the Well Qing1 to Qi8 area, Changji-Urumqi-Fukang coal mine in the southern basin margin and western slope to hinterland; and the relatively CBM-rich blocks of Badaowan Fm. are mainly in the basin hinterland. This kind of areas has favorable CBM enrichment conditions and great CBM development potential.

Class III block/CBM-bearing block Blocks with relatively methane-rich coalbeds with the Langmuir volume of $8-15 \mathrm{~m}^{3} / \mathrm{t}$. The CBM-bearing blocks of the Badaowan Fm. are mainly distributed in the middle-eastern coal field in the southern Junggar Basin margin, coal field in the eastern Junggar Basin and Dushanzi to northwestern marginal slope; the CBM-bearing blocks of the Xishanyao Fm. are mainly in the west of southern basin margin, middle Shihezi to Well Qing1 and eastern Hutubi South to Fukang South areas, where the development value of the shallow CBM is limited, but the coalbeds in deep formations with large thickness and good burial conditions (500-1500 m) are favorable for coalbed gas generation and accumulation, in some areas considerable amount of methane gas may be even sourced out to form CBM-rich block with development potential.

Class IV block/CBM-poor block Blocks contain methanebearing to methane-poor coalbeds with the Langmuir volume $<8 \mathrm{~m}^{3} / \mathrm{t}$. The CBM-poor blocks of Badaowan Fm. are mainly distributed in the Sikeshu area in the west of southern basin margin; and the CBM-poor blocks of Xishanyao Fm. are in a small range. In these areas, the CBM has small or even no value as the coalbeds have low gas storage capacity and poor gas-bearing property.

In a word, the low-rank CBM development in Junggar Basin is deemed to have great potential. The highest measured gas content of the coal reservoir in this area (Table 3) approaches the CBM adsorption in three lowrank coal basins of the US being commercially developed (2.1-14.7 $\mathrm{m}^{3} / \mathrm{t}$ in San Juan Basin, 9.1-15.6 $\mathrm{m}^{3} / \mathrm{t}$ in Warrier Basin, and 5.6-12.6 $\mathrm{m}^{3} / \mathrm{t}$ in Pisons Basin), and the largest gas content of the Xishanyao Fm. is much higher than Badaowan Fm. The areas with CBM resource prospect should be mainly preferred in Class II (relatively CBM-rich) and Class I (CBM-rich) blocks with the Langmuir volume more than $15 \mathrm{~m}^{3} / \mathrm{t}$. 


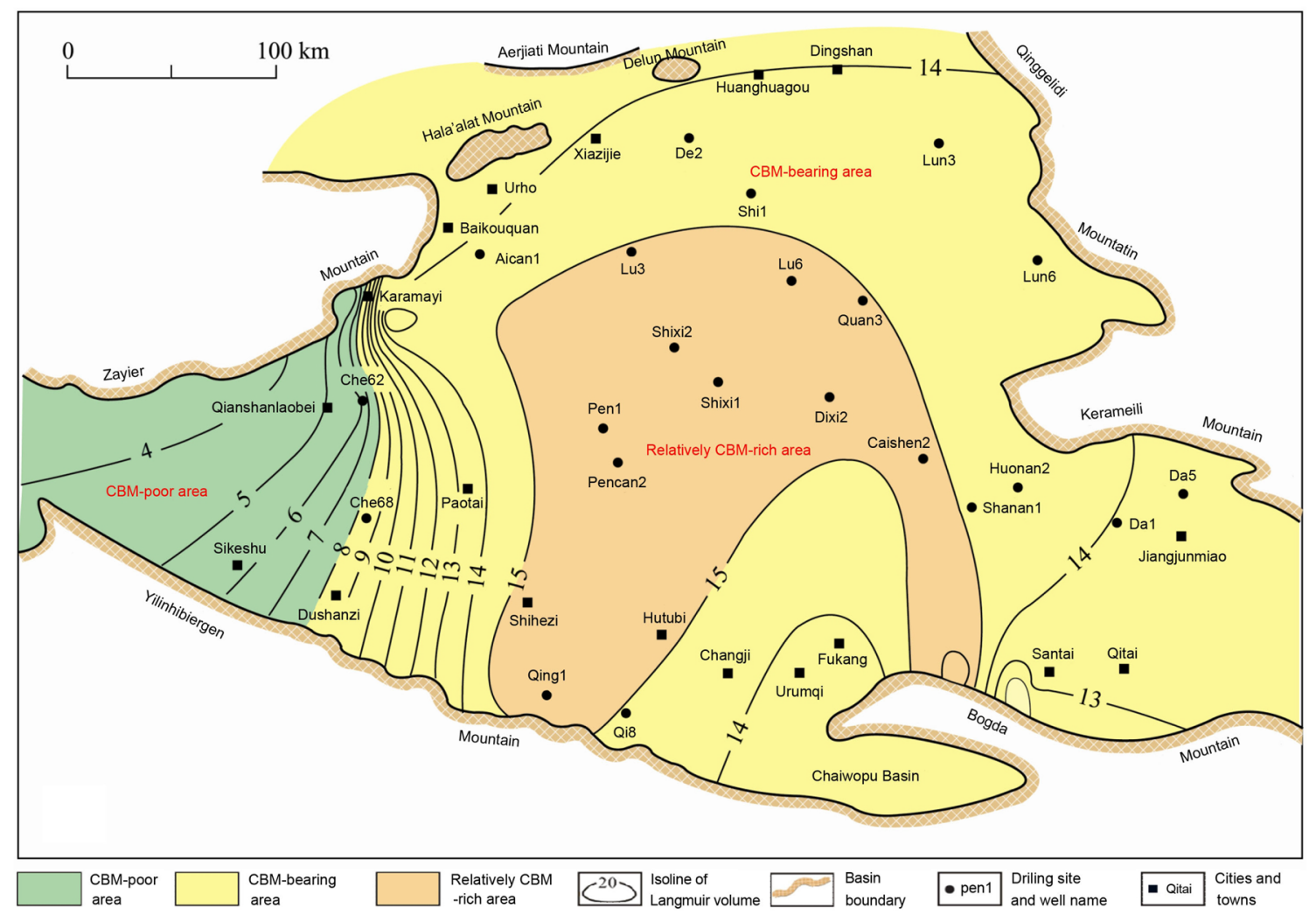

Fig. 6 Isogram of Langmuir volume distribution in the $\mathrm{J}_{1} \mathrm{~b}$ coal reservoir in Junggar Basin, NW China

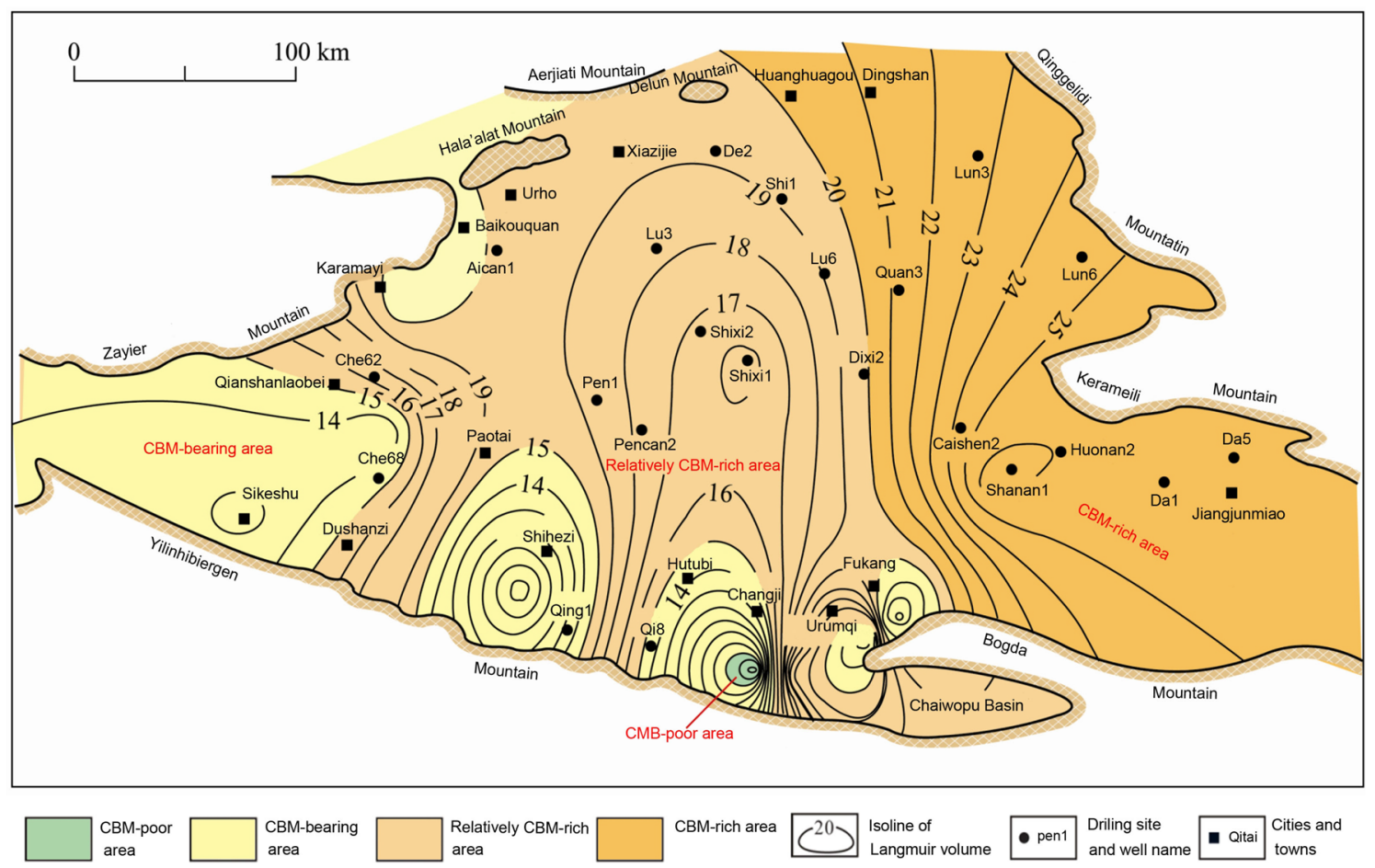

Fig. 7 Isogram of Langmuir volume distribution in the $\mathrm{J}_{2} \mathrm{x}$ coal reservoir in Junggar Basin, NW China 


\section{Thinking and models of CBM exploration}

It can be seen from the above that the coal seams in Junggar Basin are deeply buried in the abdomen and south margin (Figs. 3, 4), but they also have the characteristics of coal (CBM), oil and gas coexisting with the basin. According to Yang et al. (2019), shallow CBM has the characteristics of three gas sources replenishment, which are biogas, thermogenic gas and deep migration gas. In addition to adsorbed gas, there is a large number of free gas in coal seam. Deep CBM has the characteristics of two gas sources replenishment, which are thermogenic gas and deep migration gas. They have formed gas pools with symbiosis of adsorbed gas and free gas, which are obviously different from the lowrank CBM basins in the USA and have possessed Chinese characteristics.

Therefore, the exploration mode of combining depth and shallow and combining conventional gas and unconventional gas is adopted to carry out district evaluation, and to find the favorable target area from the perspective of the synergistic effect of oil-gas exploration and exploration benefit. It is preliminarily considered that exploration of adsorbed gas is the first, then explored the free gas in shallow strata; while in deep strata, the exploration of free gas in Xishanyao Fm. is mainly, to search for lithologic traps or structural traps; the $\mathrm{CBM}$ and sandstone gas are explored together in Badaowan Fm., in order to improve the utilization rate of resources.

\section{Achievements application and latest progress}

In recent ten years, the above achievements and understandings have been gradually recognized and applied. As for the shallow CBM exploration in the southern margin and the east, as well as the deep CBM exploration in eastern Junggar Basin, remarkable progress has been made.

Based on the evaluation of CBM resources and favorable areas, the Sha'nan-Shazhang, Baijiahai and Wutongwozi areas in the eastern Junggar Basin were selected to carry out deep CBM exploration. And the Liuhuanggou in Changji area at the southern margin were selected as shallow CBM exploration. A parametric well has been constructed in Shazhang and Dajing areas, respectively. And gas content and well test have been carried out (Zhang 2016). In 2008, the shallow CBM gas was extracted from Dahuangshan coal mine at $2000 \mathrm{~m}^{3} / \mathrm{d}$ in the southern Junggar Basin margin, obtaining the first well with industrial CBM gas flow.

As for the exploration domain of shallow CBM, the CBM exploration and pilot test of development in Junggar Basin have been continued to carry out (Lin et al. 2016) since 2011. The Baiyanghe CBM demonstration project in Fukang area was constructed. Nearly 100 CBM wells have been implemented, such as the parametric well drilling in eastern of Urumqi River (well Wucan 1, Wucan 2), Baiyanghe test well group in Fukang mine (well Fucan 1, etc.), Dahuangshan mine (well Fumei 1), Que'ergou mine in Hutubi (well Changshi 1, well Changshi 2) and Liuhuanggou mine in Changji as well as well group drilling of Kelinside New Energy Co., Ltd. in the western Fukang mining area. CBM exploration and development in the junction area between East and south of Junggar Basin have shown favorable prospects. Among them, in 2014, small-scale development of CBM in the west of Baiyanghe in Fukang mining area was carried out. The highest gas production rate of SCD01 well was $1.72 \times 10^{4} \mathrm{~m}^{3} / \mathrm{d}$, which made a major breakthrough (Chen et al. 2017), but it was difficult for gas wells to stabilize production.

As for the exploration domain of deep CBM in eastern Junggar Basin, following the thought of "stereoscopic exploration of both absorbed gas and free gas," Well Cai 512 was drilled in Baijiahai area, which produced $4420 \mathrm{~m}^{3}$ gas from $\mathrm{J}_{2} \mathrm{x}$ coalbed after fracturing. The coalbed in the well is buried at 1300-3000 m deep and develops 5-20 m thick with large amount of free gas at coal-rich center. It belongs to semi-dull coal with a Ro of $0.52-1.05 \%$, ash yield of $4.24 \%$ on average, Langmuir volume of $7.98 \mathrm{~m}^{3} / \mathrm{t}$ on average, Langmuir pressure of 5.8 MPa on average, and real measured gas content of $14.73 \mathrm{~m}^{3} / \mathrm{t}$. The well marks the breakthrough of deep CBM exploration in this area, demonstrating the potential of low-rank CBM.

Over the past three years, the project of "research on low-rank coal seam gas content prediction technology in Fukang" has been completed and put forward the theory and method suitable for the prediction of low-rank coal seam gas content in Xinjiang. The first pilot demonstration project of CBM exploitation in Xinjiang-CBM collecting and transporting booster station in Baiyanghe mine, Fukang city, has progressed smoothly, and the annual production capacity is expected to reach $3000 \times 10^{4} \mathrm{~m}^{3}$ after completion.

In 2017, the well Xinwucan 1 deployed by the China Geological Survey on the Xishan monoclinic structure in the western Urumqi River of southern Junggar Basin has made significant progress. $428.70 \mathrm{~m} / 19$ seams with high gas content and low rank has been drilled. And $40 \mathrm{~m}$ reservoir with four sections in No. B7 coal seam was optimized to carry out segmented hydrofracture and combined layer drainage. As a result, the high-yield industrial gas flow of $3372 \mathrm{~m}^{3} / \mathrm{d}$ was obtained, and the stable output was $3200-3300 \mathrm{~m}^{3} / \mathrm{d}$ (Shan et al. 2018).

At present, a series of CBM exploration activities has been carried out across Junggar Basin. Following Qinshui Basin and Baode Basin, Junggar Basin has become the third largest CBM development hotspot area in China. 


\section{Conclusions}

1. There develop relatively prospective low-rank coal reservoirs in Badaowan Fm. $\left(\mathrm{J}_{1} \mathrm{~b}\right)$ and Xishanyao Fm. $\left(\mathrm{J}_{2} \mathrm{x}\right)$ with Ro mostly less than $0.8 \%$, stable and mostly thick to very thick recoverable coalbeds in southern and eastern Junggar Basin. They are multiple in layer, thick in single layer and cumulative series, stable in distribution and become more developed from northwest to southeast. The coal seams possess moderate burial depth and high gas content; dominated by middle-low ash content, low sulfur content, low rank and long flame coal, with high coal type in the south and east, while low in the northern and west regions.

2. Pores in the Jurassic coal reservoirs mainly include small-micro- $(<100 \mathrm{~nm})$ and large ones, dominated by large-medium ones. The coal reservoirs have both macro- and micro-fissures, leading to great variation of permeability. The shallow coal reservoirs are mostly undersaturated, and the gas saturation tends to increase toward the deep coalbeds.

3. The coal reservoirs, with saturated adsorption volume of $10.64-17.97 \mathrm{~m}^{3} / \mathrm{t}$ on average, have strong methane gas adsorption and storage capacity. The $\mathrm{J}_{2} \mathrm{x}$ coal reservoir has higher CBM adsorption and desorption capacity than $\mathrm{J}_{1} \mathrm{~b}$, better gas storage property and is easier to develop. The Changji-Urumqi-Fukang and Well Qing1-Qi8 in the southern margin and slope to hinterland in the northwestern margin are relatively CBM-rich blocks(class II blocks), and the Cainan-Balikun coal mine in the eastern basin are CBM-rich blocks (class I blocks), with strong CBM storage capacity. The Xishanyao Fm. has higher Langmuir pressure than Badaowan Fm., which suggests it has stronger desorption to methane that makes the methane desorption and recovery easier.

4. The coalbeds in the basin have gas shows universally and good real gas-bearing property, and the low-rank CBM accounts for a great majority of CBM resources. Many coal mine gas, CBM seeps at outcrops and CBM show and discoveries in exploration wells; some cleats and cracks found with certain permeability, medium gas saturation, low-medium measured gas content, moderately predicted theoretical gas content, all of these factors mean considerable potential of low-rank CBM.

5. Some samples from the southern margin have gas content of $3.0 \mathrm{~m}^{3} / \mathrm{t}$ and even $16.68 \mathrm{~m}^{3} / \mathrm{t}$ to the utmost, and moderate maturity, which are similar to some American basins with medium-low-rank CMB commercial development. In the Changji-Urumqi-Fukang mine and Well Qing1-Qi8 in the southern margin, Balikun mine in the eastern Junggar as well as peripheral thick coal and deep thick coal at hinterland, the CBM exploration and development are deemed to have great potential.

6. By using the exploration mode of combining depth and shallow and combining conventional gas and unconventional gas, The good progress of low-rank CBM exploration recently have been made, such as coal gas extraction in Dahuangshan coal mine of the southern basin margin, industrial gas flow in the western Baiyanghe in Fukang block, and deep CBM breakthrough in the Baijiahai area of the eastern basin. And now Xinjiang has become the third largest CBM development heat spot area.

In summary, the Junggar Basin has relatively good potential for the exploration and development of low-rank CBM resources; the geologic and reservoir properties in middleeast part of southern margin and eastern basin are relatively favorable for low-rank CBM enrichment and high production. In the future, CBM target optimization, exploration, and production should focus on those relatively CBM-rich (class II) blocks and CBM-rich (class I) blocks in Junggar Basin, such as a moderate burial depth, simple tectonic setting, thick coal seams, high permeability, high gas saturation and high gas content. Better exploration progress of low-rank CBM indicates that this basin will become a new frontier of low-rank CBM exploration in China.

Acknowledgements Thank Prof. Liu Dameng, Prof. Huang Wenhui and Dr. Che Yao from China University of Geosciences (Beijing), as well as Prof. Hu Baolin from Anhui University of Technology for their help and support during the field investigation and indoor research. Thank PetroChina Research Institute of Petroleum Exploration and Development for permission to show this work.

Funding The author(s) disclosed receipt of following financial support for the research, authorship, and /or publication of this article: This study was financially supported by the Major oil and gas projects of PetroChina Co. Ltd, No. 2013E-050202.

Open Access This article is licensed under a Creative Commons Attribution 4.0 International License, which permits use, sharing, adaptation, distribution and reproduction in any medium or format, as long as you give appropriate credit to the original author(s) and the source, provide a link to the Creative Commons licence, and indicate if changes were made. The images or other third party material in this article are included in the article's Creative Commons licence, unless indicated otherwise in a credit line to the material. If material is not included in the article's Creative Commons licence and your intended use is not permitted by statutory regulation or exceeds the permitted use, you will need to obtain permission directly from the copyright holder. To view a copy of this licence, visit http://creativecommons.org/licenses/by/4.0/.

\section{References}

Chen MJ, Zhang JB (2003) The exploration strategy of coalbed methane of coal basin in low coal rank in northwestern China. Pet Explor Dev 30(1):18-21 
Chen JG, Qin Y, Sang SX, Fu XH, Zhu YM, Yang YG, Ju YW (2003) Exploration prospect of coalbed methane in Junggar Basin. Nat Gas Ind 23(2):127-129

Chen ZH, Jia CZ, Song Y, Wang HY (2007) Effects of tectonic uplift on physical properties of high and low rank coal reservoirs. Pet Explor Dev 34(4):461-464

Chen G, Qin Y, Hu ZQ, Li WZ, Shen J (2015) Variations of gas content in deep coalbeds of different coal ranks. Geol J China Univ 21(2):274-279

Chen ZH, Meng ZP, Zeng LJ (2017) Formation mechanism and enrichment patterns of middle-low rank coalbed methane in Southern Junggar Basin, China. J China Coal Soc 42(12):3203-3211. https ://doi.org/10.13225/j.cnki.jccs.2017.0019

Cui SH, Liu HL, Wang B, Yang Y, Ning N, Sang SX (2007) Trapping characteristics of coalbed methane in Low-rank coal of Junggar Basin. Geoscience 21(4):719-724

Feng SL, Hu AM, Huo YZ, Wang ZP, Long BL (2003) New advance in exploration and development of low rank coalbed methane resources in America. Nat Gas Ind 23(2):124-126

Fu XH, Jiao ZF, Qin Y, Zhang WH, Han XX (2005) Adsorption experiments of low rank coal under equilibrium moistures. J Liaoning Tech Univ (Nat Sci Ed) 24(2):161-164

Jia BY Jin XL, Li JW, Wu XB, Xu JJ (2015) Calculation of free gas content of low rank coal reservoirs: a case study of the southeast margin of Junggar Basin. Coal Geol Explor 43(2):33-36, 43

Li Y, Cao DY, Wei YC, Wang AM, Zhang Q, Wu P (2016) Middle to low rank coalbed methane accumulation and reservoiring in the southern margin of Junggar Basin. Acta Pet Sin 37(12):1472-1482

Lin HF, Wei WB, Li SG, Cheng LH (2016) Experiment study on pore structure of low rank coal affected to gas adsorption features. Coal Sci Technol 44(6):127-133

Liu DH, Fu JM, Xiao XM, Chen DY, Geng AS, Sun YG, Wang YP (2005) Origin and appraisal of coal derived gas and oil. Pet Explor Dev 32(4):137-141

Liu HL, Wang HY, Zhao Q, Lin YJ, Sang SX, Yong H (2010) Geological characteristics of coalbed methane and controlling factors of accumulation in the Tuha coal basin. Acta Geol Sin 84(1):133-137

Montgomery SL (1999) Powder River Basin, Wyoming: an expanding Coalbed Methane (CBM) Play. AAPG Bull 83(8):1207-1222

Qin JZ, Li ZM, Zhang ZR (2005) Contribution of various coal measures source rocks to oil and gas reservoir formation. Pet Explor Dev 32(4):131-136, 141

Sang SX, Qin Y, Fan BH, Jiang B, Fu XH, Zhang L, Xu L (2001) Features of low rank coal reservoir in limnic basins-taking Junggar and Tuha basins as example. J China Univ Min Technol 30(4):341-345

Sang SX, Qin Y, Guo XB, Chen YH (2003) Storing characteristics of Jurassic coalbed gas in Junggar and Tuha Basins. Geol J China Univ 9(3):365-372

Sang SX, Zhu YM, Zhang SY, Zhang J, Tang JX (2005) Solid-gas interaction mechanism of coal-adsorbed gas (I) - coal pore structure and solid-gas interaction. Nat Gas Ind 25(1):13-16

Shan YS, Bi CQ, Zhang JQ, Tang Y, Yuan Y, Xu YB, Pan WH (2018) Productive industrial gas flow obtained in Middle Jurassic lowrank coalbed methane seam in southern Junggar Basin. Geol China 45(5):1078-1079. https://doi.org/10.12029/gc20180516

Sun QP, Sun B, Sun FJ, Yang Q, Chen G, Yang MF, Yang YP (2012) Accumulation and geological controls of Low-rank coalbed
Methane in Southeastern Junggar Basin. Geol J China Univ 18(3):460-464

Wang JM, Zhang GY (2002) Features of coalbed methane resources of Xinjiang and their exploration \& development potential. Xinjiang Geol 20(1):7-10

Wang YT, Xie S, Liu QY, He LJ, Meng QH (2002) Analyze for low rank coalbed methane resources and its exploration potential in Junggar Basin. J Xinjiang Pet Inst 14(3):5-7, 12

Wang DZ, Yu YJ, Qin SY, Zhu QR (2003) A summary of the development of geophysical logging techniques for the coalbed methane reservoir. Acta Geosci Sin 24(4):385-390

Wang G, Yang SG, Zhang N, Shu K (2016) Geological condition and research direction of low-rank coalbed methane in Xinjiang. China Coalbed Methane 13(4):7-10

Yang Q, Liu DM, Huang WH, Che Y, Hu BL, Yu YJ (2005) Coalbed methane geology and resource comprehensive evaluation in Northwest China. Geological Publishing House, Beijing

Yang MF, Sun B, Lu J, Tian WG (2019) Comparative analysis on the enrichment patterns of deep and shallow CBM in Junggar Basin. J China Coal Soc. https://doi.org/10.13225/j.cnki.jccs.2019.0100

Yao HF (2007) Physical properties and exploration and development potential of coalbed gas reservoirs in Yangjiaping, Liulin County, Shanxi Province. Pet Explor Dev 34(5):548-556

Yu YJ, Yang Q, Liu DM, Huang WH (2001) A review on studies of coalbed methane reservoirs in China. Geol Sci Tech Inf 20(1):55-60

Yu YJ, Zhang YJ, Dong DZ, Han YK (2006) Current situation of natural gas exploration and its countermeasures in Junggar Basin. Pet Explor Dev 33(3):267-273, 288

Yu YJ, Wang YH, Yang Q, Liu DM, Hu BL, Huang WH, Che Y (2008) Adsorption characteristics of low-rank coal reservoirs and coalbed methane development potential, Junggar Basin. Pet Explor Dev 35(4):410-416

Yuan Y, Tang Y, Shan YS, Zhang JQ, Cao DY, Wang AM (2018) Coalbed methane reservoir evaluation in the Manas mining area, southern Junggar Basin. Energy Explor Exploit 36(1):114-131

Zhang C (2016) Reservoir forming condition and favorable prediction in the area of east Junggar Basin. Dissertation, China University of Geosciences (Beijing), pp 14-16

Zhang Q, Yang XL (1999) Isothermal adsorption of coals on methane under equilibrium moisture. J China Coal Soc 24(6):566-570. https://doi.org/10.13225/j.cnki.jccs.1999.06.002

Zhang XM, Zhuang J, Zhang SA (2002) Geology and resource evaluation of China CBM. Science Press, Beijing, pp 38-39

Zhang XM, Feng QH, Wang XS, Du P (2013) Establishment and application of material balance equations for low-rank coalbed methane reservoirs. Nat Gas Geosci 24(6):1311-1315

Zhao MJ, Song Y, Su XB, Liu SB, Qing SF, Hong F (2005) Differences for geochemical controlling factors between coal bed and conventional natural gases. Pet Explor Dev 32(6):21-24

Publisher's Note Springer Nature remains neutral with regard to jurisdictional claims in published maps and institutional affiliations. 